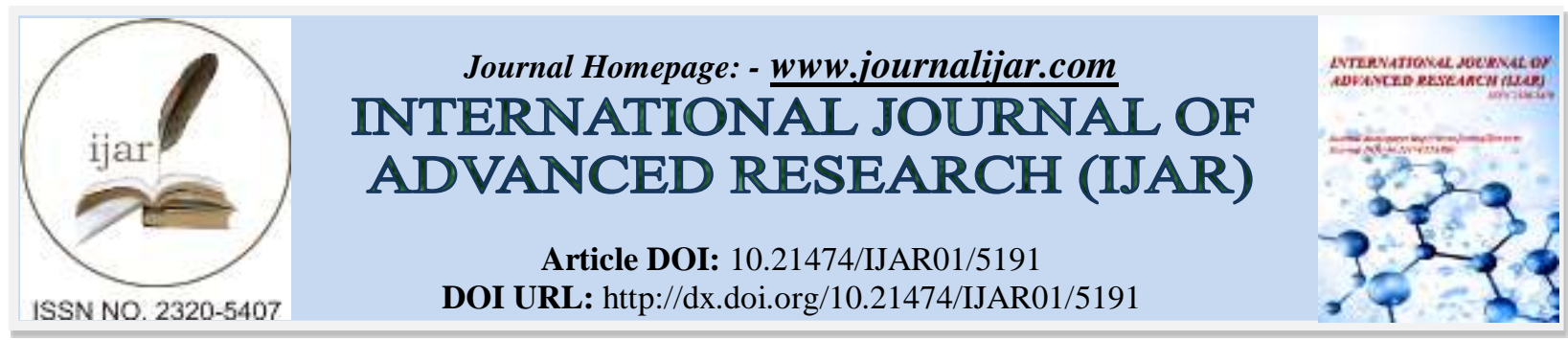

RESEARCH ARTICLE

\title{
ANAESTHETIC MANAGEMENT OF A CASE OF LARGE BENIGN THYROID MASS WITH DIABETES MALLITUS - AN ANTICIPATED DIFFICULT AIRWAY PATIENT.
}

\author{
Dr. Chanshetty rajnish (sr, md anaesthesia), Dr. Hetal parikh (professor) and Dr. Rama upadhayaya \\ (professor \& head). \\ Department of anaesthesiology, s.b.k.s. M.i.\& r.c., sumandeep vidhyapeeth, piparia.
}

\section{Manuscript Info}

Manuscript History

Received: 16 June 2017

Final Accepted: 18 July 2017

Published: August 2017

Key words:-

Ridge splitting, Expansion, Guided bone regeneration.

\begin{abstract}
Background: Several modifications have been applied to the ridge splitting with or without expansion technique to allow for implant placement in the atrophic ridges. Some studies utilized guided bone regeneration and others not. Aim: This systematic review will try to present the different studies discussing the effects of conjunction of bone grafting materials and/or membranes or not with the ridge splitting with or without expansion for patients having insufficient bucco-palatal ridge width. Methods: A thorough PUBMED (Medline) and COCHRANE databases search in addition to hand-search of journals of relevance was performed on related terms in the period from 1992 to 2016 and resulted in 3247 titles of which 21 abstracts were selected and collected as full articles for further evaluation while the rest were excluded by title or abstract. According to the inclusion criteria 14 studies were included and discussed in this article. Results: Of the 14 studies included in the present study only one study (cohortretrospective) compared ridge splitting with/without expansion technique alone and with guided bone regeneration. Twelve studies applied guided bone regeneration while three studies did not.
\end{abstract}

Copy Right, IJAR, 2017,. All rights reserved.

\section{Introduction:-}

- Diseases of the thyroid like goiters (from the Latin word guttur meaning throat) and thyroid mass still exist in many endemic parts of the world.

- A large thyroid mass did compress and deviate the trachea causing breathing difficulty, swallowing difficulty in our patient that made intubation and extubation both difficult.

- In addition to endocrine and metabolic effects, the mass extends sub-sternally which makes more challenges for the anesthesiologist to manage the airway. Up to $45 \%$ of goiter patients may have a sub-sternal component. ${ }^{[3]}$ Amathieu et al. reported that the overall incidence of difficult intubation in thyroid surgery was $11.1 \%$. ${ }^{[4]}$

- The anesthesiologist approaching the patient with a difficult airway has a vast armamentarium of techniques and instruments that can be applied to securing and maintaining oxygenation and ventilation. We describe here the presentation, diagnosis, peri-operative management and outcome of the patient who was managed with an fiberoptic intubation and extubation. 


\section{Case Report:-}

- A 42 year old, weighing $75 \mathrm{~kg}$, female patient presented with a 5-year history of neck swelling and with a rapid increase since 2 months. She was diagnosed of having diabetes 3 years back for which she was taking tablet metformin and tablet glimipride BD and was under control. She was diagnosed a case of Benign Thyroid lesion and advised surgery.

- On examination, patient was conscious, co-operative.

- Pulse - 90/min Regular

- Blood Pressure - 110/70 mmHg.

- ECG showed sinus rhythm.

- She had no stridor and no respiratory difficulty, even on lying down.

- The neck swelling was $15 \mathrm{~cm} \times 10 \mathrm{~cm}$ in size with its lower border upto the upper border of the sternum, superiorly upto the upper border of thyroid cartilage.

- Airway examination - Mouth Opening - Two and Half fingers breadth,

- Mallampati score - Grade II,

- There was limited neck extension and severely restricted neck flexion
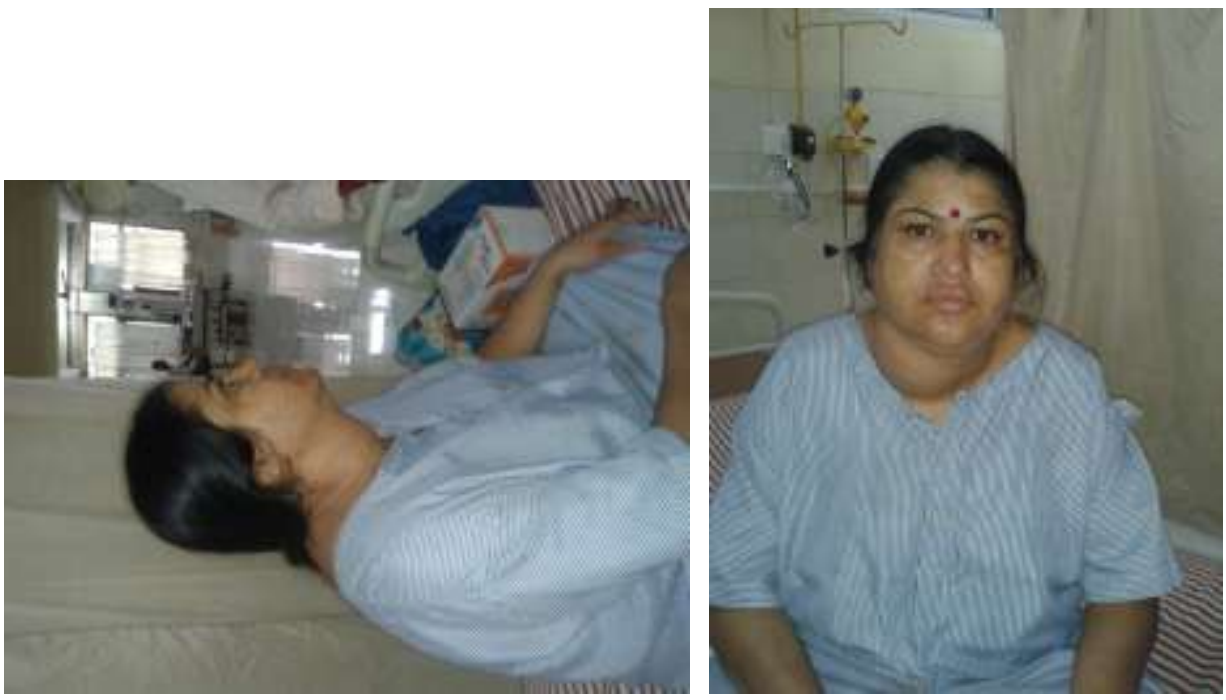

- X-ray of the neck AP revealed trachea deviated markedly to the left, lateral view revealed no compression of trachea.

- Indirect laryngoscopy - normal vocal cord movements.

- USG thyroid - large heterogeneous predominantly hyperechoiec lesion with few cystic areas and tiny calcifications that replaces normal right thyroid parenchyma. Right lobe of thyroid $10 \times 4.5 \times 6 \mathbf{~ c m}$ in size and left lobe is of $3.1 \times 1.5 \times 1.5 \mathrm{~cm}$ In size and no retrosternal extension. There is displacement of trachea towards left side and right carotid artery towards right side. 

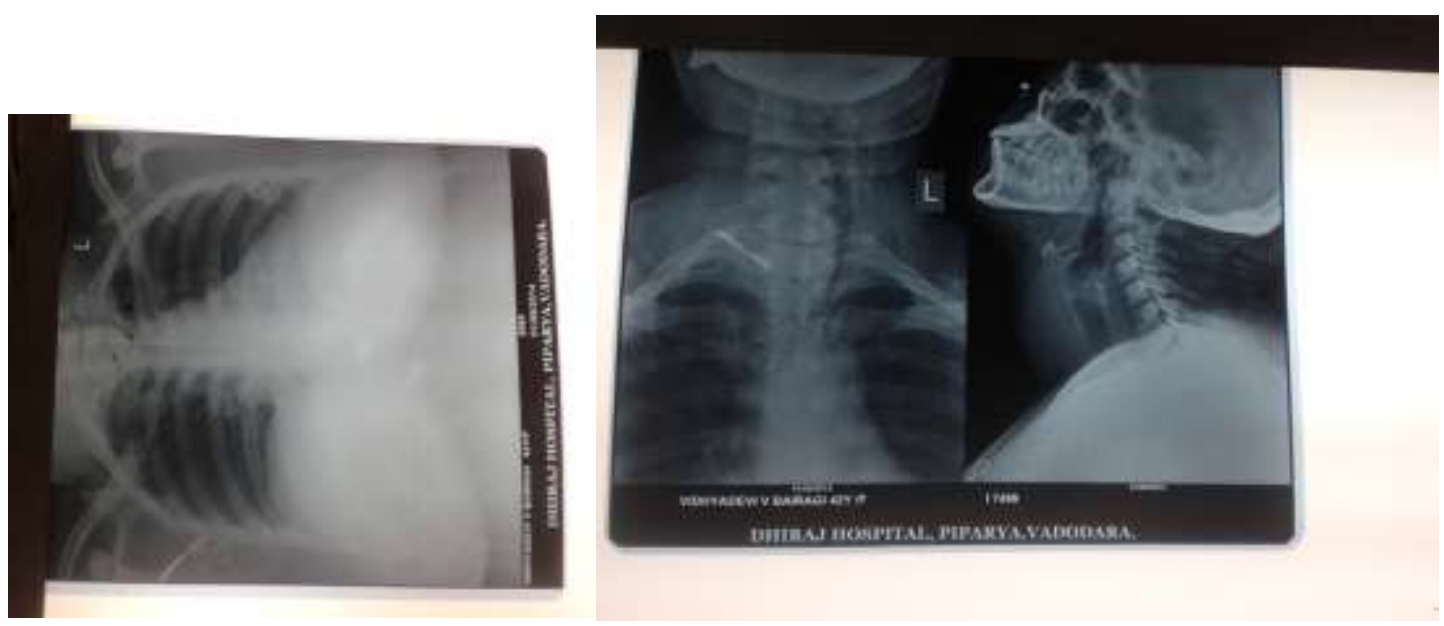

- $\quad$ FNAC shows overall Benign Thyroid Lesion.

- Hb $12.9 \mathrm{~g} / \mathrm{dl}$ TLC 9200 cells/cumm platelets 3.34 lacs/cumm

- Urea $16 \mathrm{mg} \%$ creatinine $1.1 \mathrm{mg} \%$

- $\quad$ SGPT $19 \mathrm{IU} / \mathrm{l}$ SGOT $32 \mathrm{IU} / \mathrm{l}$ Total bilirubin $0.4 \mathrm{mg} \%$

- Electrolytes Na -137 mmol/L, K - $4.3 \mathrm{mmol} / \mathrm{L}, \mathbf{C l}-104 \mathrm{mmol} / \mathrm{L}$

- HBA1C - 8.86

Thyroid profile $\mathrm{T} 3$ (total) $-1.8 \mathrm{ng} / \mathrm{ml}$

- $\mathrm{T} 4$ (total) $-8.9 \mu \mathrm{g} / \mathrm{dl}$, TSH $-0.463 \mu \mathrm{IU} / \mathrm{ml}$

- $\quad$ RBS - $208 \mathrm{mg} / \mathrm{dl}$

- On the day of surgery, no preoperative sedation was prescribed.

- Patient was put on HAI according to sliding scale and advised to omit morning dose of Insulin

- Morning FBS on the day of surgery was $146 \mathrm{mg} / \mathrm{dl}$

- Difficult airway management cart was kept ready with McCoy blade, intubating stylet, bougie, flexible bronchoscopes, and tracheostomy tubes in case of surgical invasive airway for Cannot Intubate Cannot Ventilate (CICV) scenario, and the patient was shifted onto the OT table.

- Plan A was to do a smooth conventional direct laryngoscopy and try securing the airway, whereas the alternate plan B was to use flexible fiberoptic which were ready and easily accessible.

Anesthetic management:

- After securing an IV line with 18 G IV cannula in the left upper limb, standard monitors [ECG, pulse oximeter, non-invasive blood pressure (NIBP), end-tidal carbon dioxide (ETCO2)] were attached and the baseline vitals recorded.

- Premedication Inj. Glycopyrrolate $0.2 \mathrm{mg}$ IV Inj. Ondensetron 4mg IV

Inj. Midazolam 1mg IV.

The patient's airway was anesthetized with lignocaine viscous $2 \%$ gargles and lignocaine spray (10\%) into the laryngo-pharynx.

\section{Induction:-}

Inj. Thipentone sodium 350mg IV

After confirming bag and mask ventilation

Inj. Succinyl scholine $100 \mathrm{mg}$ IV

- Than we tried to intubate the patient with 7 no armoured tube with direct larygoscopy with 4 number machintosh blade but it was unsuccessful.

- After adequate bag and mask ventilation we again tried to intubate the patient with 4 number McCoy blade with bougie but it was also unsuccessful. 
- Than again after adequate bag and mask ventilation a armored endotracheal tube number 7 was loaded on to the well-lubricated fiberscope. The fiberscope was advanced through the nasal route. The fiberscope was advanced into the larynx and trachea gradually till the level of the carina. The Armored tube was "railroaded" on the fiberscope into the larynx. ET tube position was confirmed through Maintenance:fiberscope, and clinically by chest auscultation and capnography

nitrous oxide and oxygen in the ratio of 4:4 in Bain's circuit Veccuronium muscle relaxant and sevoflurane inhalation anaesthetic agent.

One liter of Ringer's lactate and 1 Unit of whole blood were administered intraoperatively.

Urine output was $650 \mathrm{ml}$.

The surgical procedure was uneventful.

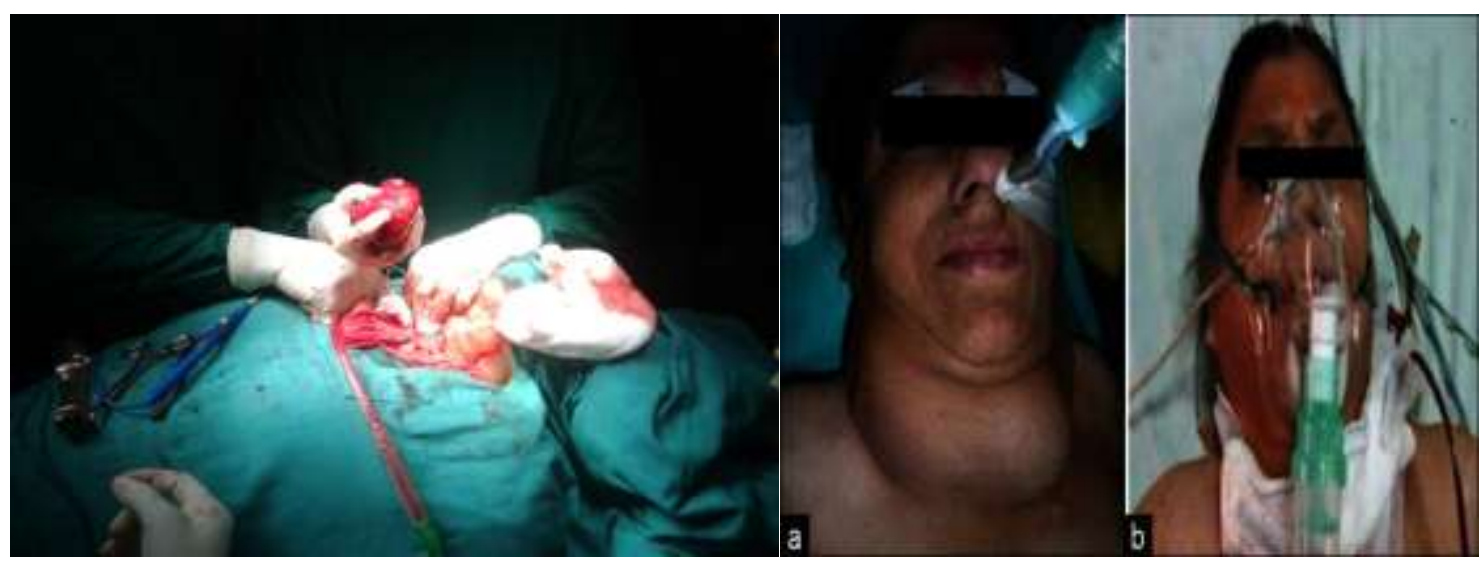

\section{Reversal:-}

At the end of the surgery, patient's muscle relaxation was antagonized using $2.5 \mathrm{mg}$ of Inj. Neostigmine and $0.4 \mathrm{mg}$ of Inj. Glycopyrrolate.

Recovery was smooth and patient was shifted to post-operative anaesthesia care unit with endotracheal tube in situ for further period of 36 hours with humidified oxygen through T-Piece in view of postoperative complication of respiratory obstruction due to tracheomalacia.

\section{Extubation:-}

Patient was extubated on 2nd postoperative day after cuff deflation demonstrated adequate leak around the tracheal tube while she was awake and breathing spontaneously. The patient was discharged on 10th postoperative day.

\section{Discussion:-}

Preoperative risk factors in a patient with large and long-standing thyroid mass (more than 3 years) are significant tracheal narrowing and/or deviation, retro-sternal extension, preoperative recurrent laryngeal nerve palsy, difficult tracheal intubation and thyroid cancer. ${ }^{[5]}$

Difficulty with intubation may be caused by an enlarged thyroid gland producing tracheal deviation, compression, or both. ${ }^{[6]}$ Amathieu et al. ${ }^{[4]}$ concluded that classical predictive criteria like mouth opening <35 mm, Mallampati III or IV, limited neck movements $<80^{\circ}$, and thyromental distance were reliable predictors of difficult airway. Management of the difficult airway presents a great dilemma for the anesthesiologist. Practice guidelines and algorithms may help in such situations. However, the anesthesiologist's judgment and vigilance remain the primary means to safe airway management.

This case had five of the six predictors for difficult airway. These factors help in predicting the difficulty associated with intubation.

Induction of general anesthesia could be risky because it may precipitate complete airway closure and make facemask ventilation and tracheal intubation impossible due to chronic pressure. Some patients with huge thyroid do not tolerate supine position due to stridor and tracheal compression. Tracheostomy may not be feasible due to 
anatomical distortion of the anterior neck as well as the inability to tolerate supine position in a few patients. ${ }^{[7]}$ For the same reason, tracheostomy was not preferred in our case.

- Another concern is tracheomalacia in these patients, which can complicate both intubation and extubation. Pressure on the trachea exerted by the neck mass can cause necrosis to parts of the tracheal wall, which can lead to complete collapse of the airway with muscle relaxation.

- To rule out tracheomalacia, leak test is performed. After deflating the cuff of endotracheal tube, note whether there is any leak on positive pressure ventilation. If despite the cuff deflation, there is no leakage of gases to gentle positive pressure ventilation, there is probability of tracheal collapse around the endotracheal tube.

- For extubation in such cases, direct visualization of airway patency is suggested. The fiberoptic bronchoscope can be used to assess for airway collapse and vocal cord movement as the endotracheal tube and bronchoscope together are slowly pulled back. If tracheal collapse is noted, the endotracheal tube and bronchoscope should be immediately readvanced and it is advisable to defer extubation.

- In our case, patient was electively kept intubated for $36 \mathrm{~h}$ in view of chances of tracheomalacia. The patient was extubated after cuff deflation demonstrated adequate leak around the tracheal tube while she was awake and breathing spontaneously.

\section{Conclusion:-}

A single universal technique of intubation may not be favourable in all circumstances. Careful selection of technique has been done as per risk versus benefit of various available techniques based on available evidence-based studies. Proper preoperative airway assessment, preparation and timely decision and skilful management reduce the morbidity and mortality in difficult airway cases involving thyroid enlargement.

\section{References:-}

1. Farling PA. Thyroid disease. Br J Anaesth 2000;85:15-28

2. Bartolek D, Frick A. Huge multinodular goiter with mid trachea obstruction: Indication for fiberoptic intubation. Acta Clin Croat 2012;51:493-8

3. Hegedüs L, Bonnema SJ. Approach to management of the patient with primary or secondary intrathoracic goiter. J Clin Endocrinol Metab 2010;95:5155-62.

4. Rosenblatt WH. Airway Management. In: Barash PG, Cullen BF, Stoelting RK, editors. Clinical Anaesthesia. $4^{\text {th }}$ ed. Philadelphia: Lippincott Williams \& Wilkins; 2001. p. 619

5. Abdel Rahim AA, Ahmed ME, Hassan MA. Respiratory complications after thyroidectomy and the need for tracheostomy in patients with large goitre. Br J Surg 1999;86:88-90

6. McHenry CR, Piotrowski JJ. Thyroidectomy in patients with marked thyroid enlargement: Airway management, morbidity, and outcome. Am Surg 1994;60:586-91.

7. Heidegger T, Gerig HJ. Algorithms for management of the difficult airway. Curr Opin Anaesthesiol 2004;17:483-4. 